\title{
Potential of different energy saving strategies in heated greenhouse
}

\author{
C. Gilli1,a, F. Kempkes², P. Munoz ${ }^{3}$, J.I. Montero ${ }^{3}$, F. Giuffrida4, F.J. Baptista ${ }^{5}$, A. Stepowska ${ }^{6}$ and \\ C. Stanghellini ${ }^{2}$
}

1Agroscope, Institute for Plant Production Sciences IPS, Conthey, Switzerland; 2Wageningen UR Greenhouse Horticulture, Wageningen, The Netherlands; ${ }^{3}$ Institut de Recerca i Tecnologia Agroalimentàries, Cabrils, Spain; ${ }^{4}$ Dipartimento di Agricoltura, Alimentazione e Ambiente, Università di Catania, Catania, Italy; ${ }^{5}$ Departamento de Engenharia Rural, Escola de Ciências e Tecnologia, Universidade de Évora and ICAAM, Évora, Portugal; ${ }^{6}$ Research Institute of Horticulture, Skierniewice, Poland.

\begin{abstract}
In heated greenhouses, large amounts of energy are used to optimize climate conditions (temperature, humidity). In conventional tomatoes production, the estimated annual energy consumption is $320 \mathrm{kWh} \mathrm{m}^{-2}$ in France, with large differences across regions, $400 \mathrm{kWh} \mathrm{m}^{-2}$ in Brittany and $240 \mathrm{kWh} \mathrm{m}^{-2}$ in the South (ADEME, 2007). In Switzerland, it varies between 245 and $500 \mathrm{kWh} \mathrm{m}^{-2}$ according to the regions. With increasing energy prices and environmental concerns, growers have to find solutions to reduce their energy use and to improve the energy efficiency. Several axes could be used to achieve this goals, one of them is climate management. Within the working group "Energy saving and neutral production" of the Cost Action FA 1105 "BioGreenhouse", a review on the potential for energy saving in heated greenhouse thanks to climate management was done. Basically, there are two ways to reduce energy consumption: related to temperature control and to humidity control. The energy saving potential of lowered day and night temperature set points, temperature integration (TI) and screen management will be presented in relation to the effects on production. In Switzerland, three trials from 2006 to 2008 in tomato crops showed that an energy saving potential of 15 to $30 \%$ could be achieved with TI compared to the standard temperature treatment. An energy saving between 23 and $30 \%$ with screens management based on external temperature and light intensity compared to a management according to the sunrise was obtained. To reduce energy consumption related to humidity control, dehumidification with heat recovery was studied. A traditional dehumidification (ventilation and heating) was compared with dehumidification with a heat pump in tomatoes crop. In 2013, 15\% energy saving was achieved with the dehumidifier and in 2014 reached $25 \%$. No difference in plant growth, yield and fruit quality was measured.
\end{abstract}

Keywords: temperature integration, screen, dehumidification, tomato, energy efficiency

\section{INTRODUCTION}

In heated greenhouses, large amounts of energy are used to optimize climate conditions (temperature, humidity). In conventional tomatoes production, the estimated annual energy consumption is $320 \mathrm{kWh} \mathrm{m}^{-2}$ in France, with large differences across regions, $400 \mathrm{kWh} \mathrm{m}^{-2}$ in Brittany and $240 \mathrm{kWh} \mathrm{m}^{-2}$ in the South (ADEME, 2007). In Switzerland, it varies between 245 and $500 \mathrm{kWh} \mathrm{m}^{-2}$ according to the regions. With increasing energy prices and environmental concerns, growers have to find solutions to reduce their energy use and to improve the energy efficiency. Several axes could be used to achieve these goals, one of them is climate management. Regarding organic greenhouses, few data are available on energy consumption. There is also little research dedicated to energy saving strategies in organic greenhouses. Part of the results obtained in conventional greenhouses are transferable to the organic greenhouses.

a E-mail: celine.gilli@agoscope.admin.ch 